\title{
ОРГАНИЗАЦИОННО-ЭКОНОМИЧЕСКИЕ ФОРМЫ И ФУНКЦИИ ЕСТЕСТВЕННОЙ МОНОПОЛИИ В КАПИТАЛИСТИЧЕСКОЙ ЭКОНОМИКЕ
}

\author{
(C) 2021 Буркеева Раиля Габдуллатыфовна \\ старший преподаватель кафедры экономической теории, региональной и отраслевой экономики \\ Оренбургский государственный университет, Россия, Оренбург \\ E-mail:r.burkeeva@mail.ru
}
(c) 2021 Булганина Светлана Николаевна
доктор экономических наук, доцент
E-mail: sn_bulga@mail.ru

В статье показаны изменения в организационно-экономических формах естественной монополии (на примере преимущественно газовой отрасли) в капиталистической экономике. При этом отмечается зависимость этих изменений от господствующей в тех или иных странах концепции прав собственности: континентальной или англо-саксонской, а, также, от изменений технологического способа производства и роли государства, осуществляющего реформы естественной монополии в капиталистической экономике. Делается вывод о том, что эволюция организационноэкономической формы естественной монополии повлияла на ее характер как регулируемой фирмы и ее функции в экономике.

Ключевые слова: естественная монополия, регулируемая фирма, организационно-экономическая форма, сетевая структура, функции естественной монополии.

Актуальность анализа капиталистической естественной монополии, которую, как правило, определяют как технологическую монополию, обусловлена рядом проблем, которые испытывает современная отечественная экономика в связи с преобладанием в ее структуре естественномонопольных отраслей, образующих ее ядро. При этом необходимость ослабления влияния естественных монополий, особенно в добывающем секторе, на российскую экономику и не отрицается, и не инициируется правительством РФ. Пока нет ни мотива, ни интереса, ни инструментов реформирования естественной монополии в направлении ее становления регулируемой фирмой и рыночным субъектом. Здесь обращение к опыту преобразований естественной монополии и его результатам в странах с капиталистической экономикой является необходимым и своевременным.

О методологии исследования. Мы исходим из предпосылки о двойственной природе естественной монополии как феномена капиталистической, рыночной экономики. Она представляет собой единство технологической основы (положительный эффект масштаба) и доступа к свободно невоспроизводимым ресурсам, принадлежащим, как правило, обществу, что делает естественную монополию регулируемой фир- мой, независимо от формы собственности на ее активы. Социально-экономическая природа естественной монополии отражается в многообразии её функций, определяющих, в свою очередь, организационно-экономические формы естественной монополии. Эти последние формируются, по мере развития капиталистической экономики, под влиянием сложившихся правовых традиций собственности: континентальной и англо-саксонской. При этом мы выделяем «родовые» (производство и реализация квазиобщественных благ, функция получения справедливой прибыли) и «приобретенные» (системообразующая, затратообразующая) функции естественной монополии. «Родовые» функции определяются самой природой естественной монополии, ее происхождением (концентрацией производства и технологической основой - положительным эффектом масштаба) и существенной чертой естественной монополии - доступом к свободно невоспроизводимым ресурсам. Отсюда главная ее функция - производство социально значимых (квазиобщественных) благ. Исторически «приобретенные» функции естественной монополии обусловлены ее эволюцией под влиянием технологических, политических, институциональных изменений в капиталистической экономической системе. В 
результате этих изменений естественные монополии оказываются на том или ином этапе развития в «центре» экономики, определяя в ней отраслевые пропорции, направления движения общественного капитала и уровень цен (системообразующая и затратообразующая функции).

Естественная монополия, как способ организации трансакций по поводу доступа к свободно невоспроизводимым ресурсам, формировалась двумя способами: путем установления контроля над собственностью, либо в форме налаживания взаимовыгодных контрактных отношений на открытом рынке.

Исходным пунктом институциональных изменений на рубеже XIX и XX вв. явилось перерастание капитализма свободной конкуренции в монополистический капитализм. С одной стороны, под влиянием технического переворота последней трети XIX века сформировались объективные условия для создания крупных предприятий промышленности и налаживания массового производства, с другой,- новые методы производства обусловили развитие акционерного капитала и возможность аккумулирования вложений капитала для создания крупного производства. Монополизация промышленного производства происходила в разных странах разными темпами и в разных формах, в зависимости от их правовых, национальных и культурных особенностей. Для европейских стран (Германии, Франции), где рыночный механизм дополнялся или замещался государственным участием в экономике, характерным было образование картелей в отраслях добывающей и, связанной с ними, тяжелой промышленности. В.Ленин характеризовал картели как союзы монополистов, которые заключают неявные долгосрочные соглашения по поводу ограничения производства компаний-участников, единых условий продажи, распределения рынков сбыта [1]. С дальнейшим обобществлением производства картель «вырабатывается» в синдикат, где предприятия сохраняют свою хозяйственную самостоятельность в производстве, но объединяются на стадии реализации продукции через сбытовую сеть одного из участников. Как было отмечено, концентрация производства под влиянием роста производительных сил сопровождалась образованием акционерных обществ, а, значит, и централизацией капитала. Так, в основе становления германской индустрии лежало масштабное строительство именно железных дорог - исторически одной из первых инфраструктурных, естественно-монопольных отраслей. По форме собственности железные дороги становились казенными предприятиями, а некоторые, после государственного финансирования их строительства, национализировались в рамках «государственного социализма», поэтому в Германии не было необходимости в специальных регулирующих органах такого рода монополий.

В США, в стране с классической моделью рыночной экономики, образование трестов, как отраслевых монополистических союзов, происходило в форме слияния ранее независимых компаний в области добычи, переработки и использования свободно невоспроизводимых ресурсов (природных ресурсов, земельных территорий и полезных ископаемых). Входящие в трест компании теряли свою хозяйственную независимость. Тресты предполагают многоступенчатую структуру управления, основанную на системе участия, где у материнской компании есть право контроля над капиталом дочерних фирм. После принятия первого антитрестовского закона Шермана тресты были преобразованы в держательские (холдинговые) компании. K началу XX века естественные монополии холдингового типа стали доминирующей организационно-экономической формой в естественно-монопольных отраслях: добыча полезных ископаемых, транспорт, инфраструктурные отрасли. Ликвидный рынок корпоративных акций становится одним из факторов внешнего контроля деятельности таких компаний и поддержания их эффективности.

Исследование эволюции организационноэкономических форм естественной монополии в условиях укрепления индустриальной системы конца XIX - начала XX века свидетельствует о том, что картели, синдикаты и тресты выступали различными ступенями монополизации промышленности [2], в том числе, тех ее отраслей, которые сейчас определяются как естественномонопольные (транспорт, электро-, водо- и газоснабжение).

В дальнейшем, в первой половине XX века, в экономике США формировались региональные, a, затем, и национальный рынок газа, что потребовало, с одной стороны, укрупнения газовых компаний вследствие конкуренции, а, с другой,соответствующих институциональных изменений в области контрактных отношений. При 
этом социально-экономические отношения на локальных рынках газа США можно трактовать как долгосрочный контракт между владельцами высокоспецифических активов: с одной стороны, независимых добывающих компаний, которые имеют специфичность местоположения и не имеют выхода на рынки сбыта. С другой,газотранспортными фирмами, как естественной монополией, ввиду крайне специализированного и негибкого характера трубопроводного транспорта газа. Согласно контракту, естественная монополия обязывалась выкупать весь газ с заявленного месторождения. Более точно систему социально-экономических отношений между государством и естественной монополией можно представить как форму общественного договора, в рамках которого государство освободило эти отрасли от действия антитрестовских законов и предоставило договор франшизы на качественное обслуживание потребителей и своевременную поставку услуг. По условиям соглашения, естественные монополии, как регулируемые фирмы, выполняли свои «родовые» функции, конечно же, стремились и к максимизации прибыли, но при этом занимались производством и реализацией социально-значимых (квазиобщественных) благ, что ставило границы их целевой функции как рыночного субъекта. Стимулом для естественной монополии, в данном случае, служило установление цены на газ по принципу «издержки плюс», то есть, на уровне затрат производителя и гарантии приемлемой нормы прибыли. Основные функции контроля над ценами продукции естественной монополии были возложены на специальные комиссии штатов.

Для естественно-монопольных отраслей экономики США были характерны и конгломератные структуры («M-form»- структура), в которых эффективное управление было возможно только на основе решения административных проблем, значительно более сложных, чем те, с которыми ранее сталкивались холдинговые компании. Организационное построение нефтегазовых компаний такого типа предполагает наиболее эффективное распределение финансовых ресурсов фирмы между отделениями и дифференцированное применение инструментов внутрифирменного стимулирования и контроля [3]. Мы предполагаем, что конгломератные образования являются неким промежуточным звеном между холдинговой компанией и меж- фирменными институциональными соглашениями, характерными уже для постиндустриального капитализма. Отмечая достоинства такого типа управления, где развитие внутрифирменного планирования соответствует постоянно изменяющейся структуре институциональной среды, К.Менар говорит, что «принятая структура, состоящая из отделов, соответствует эмпирическим наблюдениям в рамках явления, названного «революцией управляющих», то есть появлению инстанций контроля и решений, отличных от инстанций собственности; причем первые были сопряжены с подъемом техноструктуры и внутрифирменного планирования» [4]. Со второй половины XX века в США эта организационная инновация стала применяться и в естественных монополиях нефтегазового сектора.

После энергетического кризиса 1970-х гг. регулирующие органы вынуждены были ввести новые правила регулирования газового рынка, согласно которым были «либерализованы» «цены у скважины». По условиям долгосрочного контракта take-or-pay («бери или плати»), инфраструктурная сеть принимает на себя риск по объему (независимо от реальных потребностей, обеспечивает гарантии отбора большей части поставленного газа - от 80\% до 90\%). В этот период государственное регулирование газовой отрасли обеспечивало, с одной стороны, выполнение социально-экономических функций (производство и поставка социально-значимых благ) естественной монополии, с другой,- снижение стимулов менеджмента компаний, направленных на повышение эффективности отрасли.

В европейских странах с континентальной традицией прав собственности естественные монополии во второй половине ХХ в. находились в государственной (общественной) собственности, поэтому не было необходимости в специальных регулирующих органах в условиях послевоенного возрождения экономики. Но и Британская газовая компания в 1948 г. была национализирована с образованием двенадцати территориальных управлений газовой промышленности. Централизованное руководство осуществлялось Советом по газу (англ. GasCouncil), а в начале 70-х г.г. Совет был преобразован в государственное предприятие «BritishGasCorporation». Объектом многократной смены форм собственности естественные монополии становились также во Франции и в Италии [5]. Как отмечает Д.Но- 
воженов, «институциональные структуры стран находятся в достаточно жесткой зависимости от их политического устройства, поэтому в состав анализируемых переменных часто включались индикаторы типов политических систем изучаемых стран» [6], то есть, для некоторых европейских стран признание естественной монополии государственной фирмой считается необходимым и является вполне «естественным».

В странах с континентальной традицией прав собственности организационно-экономическая трансформация естественной монополии, как регулируемой фирмы, происходила путем образования концернов с функциональной унитарной структурой «U-form» - организации управления, которая представляет собой фирму и отрасль в одном лице. Развитие такого многоотраслевого капиталистического объединения было обусловлено необходимостью более тесного кооперирования различных видов производства с ограниченной номенклатурой продукции и услуг на основе использования возможностей крупномасштабного производства с единой собственностью и централизованным контролем над филиалами в целях снижения издержек управления. Правление концерна, куда входят крупные держатели акций (как правило, контрольного пакета) предприятий, в том числе, государство, осуществляет контроль и общее руководство его делами. Текущее оперативнохозяйственное управление, как известно, поручается менеджменту компании - естественной монополии.

По мере углубления процессов специализации и разделения труда, основанных на позднеиндустриальных и постиндустриальных технологических изменениях, возрастают масштабы производства и обмена, растет тенденция к потере контроля вследствие умножения иерархических уровней, происходит смешение стратегических и операционных функций в длительном и краткосрочном периоде, следствием чего появляются проблемы координации, которые становятся неразрешимыми. Так встает вопрос о дерегулировании [7].

В 1980-х годах в США, уже в условиях постиндустриального развития капитализма, два обстоятельства становятся предпосылкой либерализации газового рынка США [8]: с одной стороны, начинающие разрушаться в некоторых отраслях естественно-монопольные условия производства, с другой,- критика деятельности есте- ственных монополий со стороны научного сообщества [9]. Дерегулирование представляет собой изменение организационно-экономической структуры естественной монополии путем выделения в ней естественно-монопольного ядра [10]. Происходит технологическое, организационное и экономическое разграничение двух функций: производителя (поставщика) и транспортировщика. В результате реформирования все потенциальные клиенты имеют возможность заключать контракты на закупку газа с добывающими компаниями, а затем перебрасывать его в пункт назначения, оплачивая транспортный тариф. Владельцам транспортных компаний было разрешено участвовать в нерегулируемом газовом бизнесе только через свои филиалы, которые функционально, организационно и финансово отделены от транспортного бизнеса. Транспортные услуги, предоставляемые на недискриминационных условиях, оплачиваются по двух-ставочному тарифу, что обеспечивает суммарную плату за доступ, покрывает все постоянные расходы газопровода, а цена за транспортировку единицы продукции - только операционные издержки за эту услугу. При этом транспортные контракты можно перепродавать на вторичном рынке, а информационная прозрачность позволяет всем участникам узнать о ценовых заявках на поставку газа, доступных мощностях и т.д.

Организационно-экономической формой естественной монополии, характерной для гибридных институциональных соглашений на данном этапе выступают межфирменные сети, как специфическая форма сотрудничества и взаимозависимости между хозяйствующими субъектами на основе длительного имплицитного отношенческого контракта. Для межфирменных сетей характерны, по меньшей мере, два признака: во-первых, в сети участвуют как минимум три компании-контрагента, во-вторых, партнеры (участники) согласовывают свои функции и устанавливают долгосрочные взаимосвязи, но не объединяют их [11]. В этом случае основной проблемой выступают способы внутреннего управления межфирменных сетей, которые Менар [12] называет «властными» (authorities), подчеркивая, тем самым, их отличие от «иерархических» отношений, когда, в условиях автономии партнеров происходит передача ряда второстепенных решений отдельному юридическому лицу, отвечающему за координацию действий [13]. Таким органом в данном слу- 
чае выступает координационный совет по газу.

Таким образом, стратегия межфирменной сети на газовом рынке США, как система контрактов между экономическими агентами нацелена на экономию издержек, позволяет увеличить объемы продаж за счет экспансии на новые рынки, в том числе, международные. В то же время, в результате сохранения конкуренции, она обеспечивает оптимальную цену для потребителей.

Посмотрим на преобразования естественной монополии в Великобритании. Здесь газовая компания «BritishGas» функционировала до 1986 года как публичная вертикально-интегрированная компания. Проблемы дерегулирования газового рынка Великобритании также стали актуальными и получили освещение в работах экономистов. Так, К.Веббер [14] использовал модели рыночной интеграции газа (GMI) в качестве основы для описания эволюции британского газового рынка. А. Юрус [15] отмечал, что экспорт газа трубопроводным транспортом на основе долгосрочных контрактов препятствует развитию конкурентного рынка газа в Великобритании и подчеркивает необходимость разработки новых «механизмов гибкости» рынка.

В 1986 г. в результате принятого правительством решения о приватизации газовой компании «BritishGas» в соответствии с «Законом о газе», акции компании были размещены на Лондонской фондовой бирже, был создан отраслевой регулятор - Управление газоснабжением (Ofgas), а рынок газа был разделен на три основных сектора: оптовый, контрактный и тарифный.

Оптовый рынок газа - это сделки между производителями, торговцами, «BritishGas» и независимыми поставщиками, где природный газ реализовывался между производителями и «BritishGas на основе долгосрочных и среднесрочных контрактов. Контрактный рынок - поставки газа крупным компаниям независимыми поставщиками или «BritishGas». На тарифном рынке газа поставки осуществляются компанией «BritishGas» мелким потребителям (с годовым потреблением ниже порога для крупных потребителей). Формирование таким образом конкурентной среды на этих рынках привело к сокращению доли «BritishGas», но при этом способствовало крупным потребителям напрямую заключать контракты с производителями, что привело к реализации газа на оптовом рынке независимыми грузоотправителями, торговцами и поставщиками газа. Это привело к улучшению качества и увеличению количества предоставляемых услуг, снижению цен на природный газ. Положительный эффект рыночных преобразований на газовом рынке в 1985-1986 годах проявился в снижении цен на промышленную продукцию в результате роста объемов потребления природного газа на $38 \%$.

На рынке газа для мелких потребителей единственным поставщиком природного газа оставалась естественная монополия «BritishGas», регулируемая «Ofgas». Считалось, что на этом рынке конкуренция нецелесообразна и неэффективна, так как административные методы координации и комбинирования активов в рамках одной фирмы способствуют снижению трансакционных издержек. В то же время, «BritishGas», оставаясь естественной монополией, держала под контролем всю газопроводную систему, сохранила свое монопольное положение на рынке оптовой торговли, контрактных рынках газа и контролировала независимых поставщиков газа, тем самым препятствовала развитию конкурентного газового рынка. Таким образом, не была решена основная проблема естественной монополии: способность контролировать дискриминационный доступ к газопроводной сети. Попытки регулировать поведение естественной монополии в этот период оказались недостаточными для развития полноценной конкуренции. В начале 1990-х годов правительством были приняты меры с целью расширения доступа независимых поставщиков к природному газу, поставляемому по газопроводу от производителей, и попытаться тем самым выровнять условия конкуренции для всех производителей.

В результате рыночных преобразований у полумиллиона потребителей газа появилось право самостоятельного выбора поставщика, из них 5 тыс. сразу выбрали альтернативного поставщика. В марте 1997 года еще 1,5 млн. потребителей южной части страны получили право выбора поставщика. В 1997 году завершилась либерализация газового рынка как контрактного [16].

Реализация социально-экономических функций естественной монополии на основе различных «институциональных матриц, то есть различных соглашений, в рамках которых целиком осуществляется трансакция», на газовом 
рынке подтверждает их экономическую целесообразность. Опыт либерализации газового рынка Великобритании показывает, что оставаясь в статусе естественной монополии, «BritishGas», контролирует пропускную способность и доступ к поставкам газа, тем самым ограничивая конкуренцию. Оказалось, простое удаление административных барьеров для входа в газоснабжение и дерегулирование цен на газ является недостаточным условием для обеспечения конкуренции.

К настоящему моменту в Европе - странах с континентальной моделью отношений собственности, сложилась двухсекторная модель рынка с одновременным присутствием на нем долгосрочных контрактов с различными формулами цены и краткосрочных сделок, с явным предпочтением последних.

Специфика газового рынка Германии, как отмечает В.Фейгин, отличается многочисленностью участников. В числе компаний, работающих на газовом рынке с различной формой собственности,- 10 импортирующих, 13 добывающих, 19 газотранспортных (или, преимущественно, газотранспортных), 149 региональных распределительных и 453 локальных газоснабжающих и газораспределительных компаний [17]. При этом газопроводы в Германии являются государственными предприятиями, обладающими транспортной монополией. Газопроводы включены и интегрированы в деятельность газовой компании. В 2009 году 5 операторами газотранспортных сетей Германии была создана единая торговая площадка GASPOOL co штаб-квартирой в Берлине. Газовый рынок Германии перед реформированием был разбит на три уровня. На первом («промежуточном») уровне находились крупные вертикальноинтегрированные газовые компании, которые также активно занимались производством и/ или импортом газа для нужд региональных оптовиков и основных распределительных компаний. Эти региональные оптовые и распределительные компании поставляли газ мелким региональным и местным (муниципальным) распределительным компаниям, которые затем поставляли газ конечному потребителю. Сделки между компаниями заключались в точках пересечения на всех уровнях поставок и вращались вокруг консолидации необходимого объёма газа. Основу этих трансакций составляли долгосрочные контракты. В то же время немецкий рынок газа был по соглашению поделён на множество региональных с монопольными поставщиками. В целях обеспечения своего особого положения, компаниям приходилось гарантировать бесперебойность поставок. Вертикальноинтегрированные компании-импортёры и производящие компании могли довольствоваться минимальными денежными обязательствами по долгосрочным поставкам благодаря существующим эксклюзивным, концессионным соглашениям, заключаемым между газораспределительной компанией и муниципалитетом, и демаркационным, разграничительным соглашениям. Использование концессионных соглашений является одним из инструментов государственного регулирования инвестиционной деятельности. Эти сделки были отменены в 1998 году, а им на смену пришли долгосрочные контракты по распределению, которые, в большинстве своём, отражали условия долгосрочных импортных контрактов. Вместе с тем, их реализация вызвала необходимость использования дополнительных регулирующих мер на газовом рынке. Так, в 2006 году немецкое федеральное агентство по борьбе с картелями приняло решение, действовавшее до 30 сентября 2010 года, об ограничении долгосрочных распределительных контрактов, установив определённые временные ограничения на оговорённые контрактами объёмы. Если бы не произошло «газового перенасыщения» 2009 года, условия соглашений по долгосрочным импортным сделкам могли бы и дальше оставаться в силе, в связи с отсутствием избыточного предложения на немецком рынке. Это положение резко изменилось с приходом конкурентного, катарского сжиженного природного газа в терминалы сжиженного газа Северозападной Европы.

С 2011 года газовый рынок Германии разделён между двумя структурами: «Нэт Коннект Джормани» и «ГазПоол» [18]. В результате разукрупнения старых оптовиков-игроков рынка на промежуточном и региональном уровнях в этих двух частях рынка работает 17 операторов сетей передач. Газовый рынок теперь полностью либерализован, приватизирован и поделён. В структуре немецкого рынка объединено 7000 операторов распределительных сетей, около 800 оптовиков и поставщиков, почти 40 экспортёров и импортёров газа и почти 30 операторов систем хранения. Разделение участников рынка по видам деятельности (производство, транспор- 
тировка, снабжение и др.), их многочисленность, гибкость контрактов, многообразие пучков прав собственности, сетевая форма организации взаимодействий - все это составляющие конкурентности газового рынка.

Отслеживание этапов реформирования отраслей естественной монополии в странах с различными моделями собственности показывает, что существенные изменения, которые происходили в системе организационно-экономических форм естественной монополии, нашли специфическое отражение в реализации их «родовых» и «приобретенных» функций в этих странах.

Развитие социально-экономических функций капиталистической естественной монополии, предполагает различные меры государства по корректировке ее деятельности, то есть, регу- лирование. Более широкое толкование термина «регулирование» предполагает государственную фирму, связанную с реализацией интересов государственного сектора экономики, а узкое,- с административно-правовой регламентацией естественной монополии [19], то есть, с регулируемой фирмой. Выбор в пользу регулируемой фирмы оправдывается тем, что государство действует в общественных интересах, которые могут идти вразрез с интересами естественной монополии, как компании. Государство «должно найти баланс интересов сторон...оно должно, с одной стороны, защищать потребителей от возможных злоупотреблений естественных монополий, а с другой,- способствовать их развитию в интересах общества» [20].

\section{Библиографический список}

1. Вестфаль К. Газовый рынок Германии: перемены как решающий фактор.- Режим доступа: http://abfund. org/gazovy-j-ry-nok-germanii-peremeny-kak-reshayushhij-faktor/

2. Бутыркин А. Проблемы реформирования естественных монополий /А.Бутыркин // Мировая экономика и международные отношения. 2003. № 12. С. 4-11.

3. Заостровщев А. Рентоориентированное поведение: потери для общества//Вопросы экономики. 2000. № 5 . C.31-44.

4. Кон А. Финансовый капитал (популярный очерк): 2-е исправленное издание. М.: изд. Коммунистического ун-та им. Сверлова, 1927. 145 с.

5. Коробцов В. Зарубежный опыт регулирования деятельности естественных монополий.- Режим доступа: http://dspace.bsu.edu.ru/bitstream/123456789/10378/1/Korobtsov_Zarubezhnyi.

6. Калмычкова E. Зарубежный опыт реформирования отраслей естественной монополии на примере электроэнергетики и газовой отрасли. - URL: https://cyberleninka.ru/article/n/zarubezhnyy-opyt-reformirovaniyaotrasley-estestvennoy-m

7. Королькова Е. Естественная монополия: регулирование и конкуренция//Экономический журнал Высшей школы экономики. 2000. Т.4. № 2.

8. Кононкова Н. Естественная монополия как объект государственной собственности / Н. Кононкова, П. Кононков // Вестник МГУ. Сер.6. 2008. № 6. С. 12-20.

9. Ленин В. Империализм как высшая стадия развития капитализма. Избран.произведения в 3-х. Т. М.: Политиздат, 1973. Т.1. 843 с.

10. Менар К. Экономика организации. М.: ИНФРА-М, С 118.

11. Миловидов К. Развитие европейских рынков газа. Разнообразие национальных моделей предложения газа._- Режим доступа: http://journal.esco.co.ua/2006_7/art_80.htm

12. Митрова T. Анализ либерализации зарубежных рынков природного газа.- Режим доступа: http://www. gasforum.ru/analit/mitrova_2004.doc

13. Новоженов Д. Организационные структуры в российской экономике// Экономист. 2003. № 12. С. 65-74.

14. Уильямсон О.И. Экономические институты капитализма: фирмы, рынки, отношенческая контрактация. СПб.: Лениздат, 1996. 702 с.

15. Фейгин В. Особый путь либерализации рынка Германии // Нефть и капитал. 2005. № 3.

16. Шерешева М. Межорганизационные сети в системе форм функционирования современных отраслевых рынков. - Режим доступа: https://www.econ.msu.ru/cmt2/lib/a/715/File/11072007-Sheresheva.doc

17. Щербак А.А. Влияние естественных монополий на развитие хозяйственной системы. /Щербак А.А. // Диссертация на соискание научной степени кандидата экономических наук. - 2018. -440 с - Режим доступа: https://unecon.ru/sites/default/files/dissshcherbakaa.pdf.pdf 
18. Ménard C. The Economics of Hybrid Organizations // Journal of Institutional and Theoretical Economics. 2004. № 160 (3). P. 345-376.

19. Andrej Juris Natural Gas Markets in the U.K. Competition, industry structure, and market power of the incumbent. -URL: http://siteresources.worldbank.org/EXTFINANCIALSECTOR.

20. B.Bebber THE EVOLUTION OF THE GAS INDUSTRY IN THE UK. A case study prepared for the International Gas Union's Gas Market Integration Task Force. -URL: www.iapg.org.ar/WGC09 